\title{
EFFECT OF TETRODOTOXIN ON THE MAMMALIAN NEURO-MUSCULAR SYSTEM
}

\author{
KANAME KURIAKI AND IUKO WADA \\ Department of Pharmacology, Nippon Medical School, Tokyo \\ Received for publication April 15, 1957
}

Tetrodotoxin, the poison contained mainly in the roe of Fugu, a poisonous kind of the globefish, is known to paralyze not only the central nervous system, but also the peripheral neuro-muscular system (1-5). To date, many works have been performed on its effect on the latter system, but the amphibians have been the experimental objects in most of them. We thought it worthwhile to resume the study on a mammal, in view of the recent advances in the neuro-muscular pharmacology and of the now available new technique of Bülbring which makes it possible to study, independently from circulatory influence, the drug actions on the isolated mammalian neuro-muscular system.

\section{METHODS}

The phrenic-diaphram preparation of the rat was prepared, following the description of Bülbring (6). The square wave stimulator and the silver-silverchloride electrodes were employed for stimulation (duration : $0.05-0.1 \mathrm{sec}$, frequency: 6 stimuli $/$ min, intensity : $0.5-1.0$ V). Electrodes for indirect stimulation were at their ends shaped in loops of the diameter of the phrenic, through which the nerve was pulled. One of the electrodes for direct stimulation was attached to the diaphram near the point of its fixation; the end of the other one was set free in the bath.

The poison employed was tetrodotoxin* prepared by Sankyo Co. from the roe of Fugu through precipitation with lead acetate in methanolic ammonia and the M.L.D. of which was $3.4-3.5 \mu \mathrm{g} / \mathrm{g}$ mouse.

\section{RESULTS}

The poison in concentrations of $1 \times 10^{-6}-0.5 \times 10^{-5}$ depressed the muscular contractions produced by direct as well as indirect stimulations progressively. Finally, indirect then direct stimulation became ineffective. However, even after the complete paralysis, direct stimulation with higher intensity brought forth the muscular contraction, at times. Furthermore, when the paralyzed preparation was washed with Tyrode's solution, the muscle recovered its reactivity considerably, and the direct as well as indirect stimulation became effective.

Following compounds in concentrations indicated in parenthesis were then tested on the preparation paralyzed beforehand with $1.0 \times 10^{-5}-0.5 \times 10^{-5}$ of tetrodotoxin, in order to see whether they can antagonize the effect of the poison or not: d-tubocurarine $(0.5 ; 0.05 \mathrm{~mm})$ 


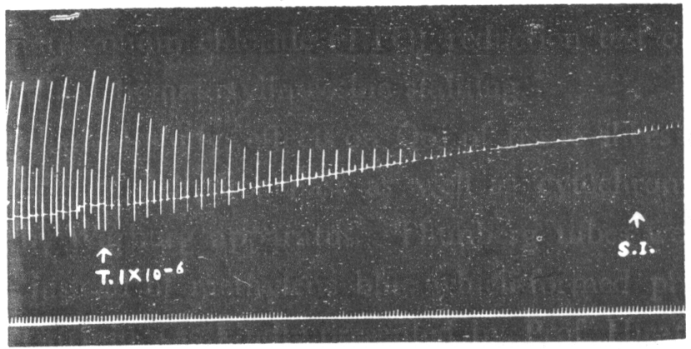

FIG. 1. Effect of Tetrodotoxin on the neuro-muscular system as studied with the phrenicdiaphragm preparation of the rat.

$\mathrm{T}$ : Tetrodotoxin $\left(1 \times 10^{-6}\right)$,

S.I. : direct stimulation of maximal intensity, Traces of larger amplitude : direct stimulation, Those of smaller amplitude: indirect stimulation,

Stimulation: duration $0.05 \mathrm{sec}$, frequency 6 stimuli/min, intensity $0.5 \mathrm{~V}$

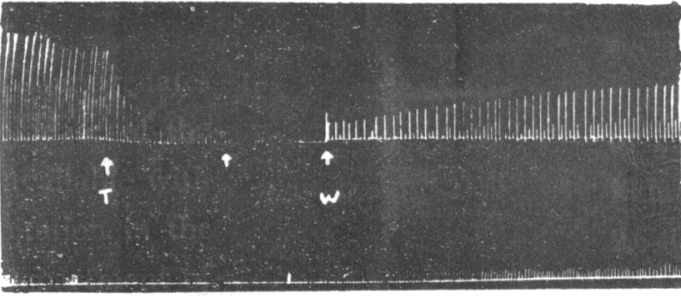

FIG. 2. Effect of Tetrodotoxin on the neuro-muscular system as studied with the phrenicdiaphragm preparation of the rat.

T : Tetrodotoxin $\left(1 \times 10^{-5}\right)$,

I : direct stimulation of maximal intensity,

W : washing,

Traces of larger amplitude : direct stimulation, Those of smaller amplitude: indirect stimulation,

Stimulation: duration $0.05 \mathrm{sec}$, frequency 6 stimuli/min, intensity $1.0 \mathrm{~V}$

(Fig. 3), decamethonium** (5.0;0.5; $0.05 \mathrm{~mm}$ ) (Fig. 4), neostigmine (50.0; $5.0 ; 0.5 \mathrm{~mm}$ ), acetylcholine $(10.0 ; 5.0 \mathrm{~mm})$, physostigmine $(1.0 ; 0.5 \mathrm{~mm})$, calcium chloride $(100.0 ; 50.0$; $10.0 ; 5.0 \mathrm{~mm})$, potassium chloride $(100.0 ; 10.0 ; 1.0 \mathrm{~mm})$, epincphrine $(5.0 ; 0.5 \mathrm{~mm})$, ephedrine $(50.0 ; 5.0 \mathrm{~mm})$, guanidine $(5.0 ; 0.5 \mathrm{~mm})$, glycocoll $(50.0 \mathrm{~mm})$, veratrine $(1.0 ; 0.5 \mathrm{~mm})$. However, none of them was effective.

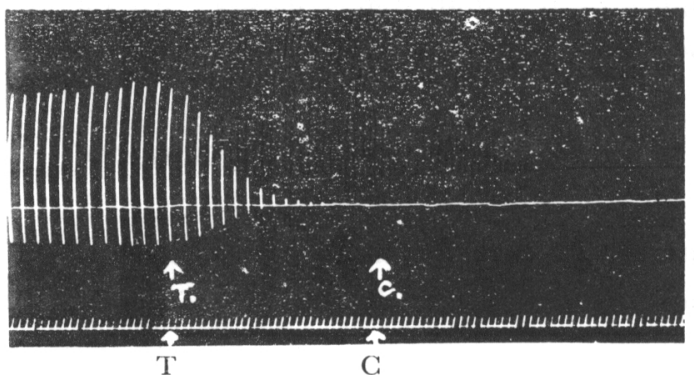

FIG. 3. $d$-Tubocurarine on the Tetrodotoxin block. $\mathrm{T}$ : Tetrodotoxin $\left(1 \times 10^{-5}\right)$,

$\mathrm{C}: d$-Tubocurarine $(0.5 \mathrm{mM})$

Stimulation (indirect) : duration $0.1 \mathrm{sec}$, frequency 6 stimuli/min, intensity $1.0 \mathrm{~V}$

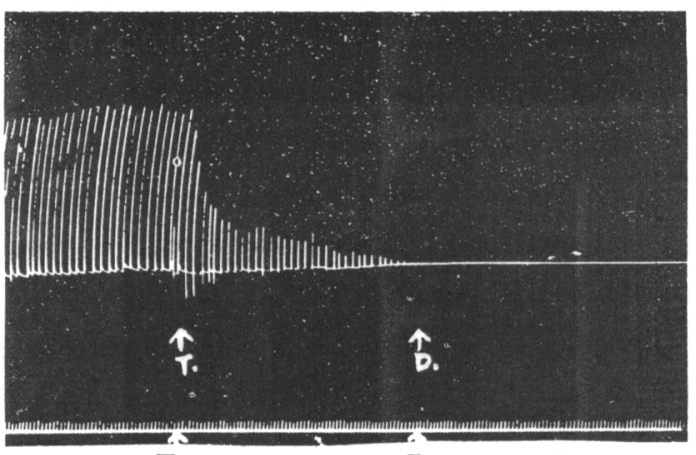

$\mathrm{T}$

FIG. 4. Decamethonium on the Tetrodotoxin block. $\mathrm{T}$ : Tetrodotoxin $\left(0.5 \times 10^{-5}\right)$,

$\mathrm{D}$ : Syncurine $(0.5 \mathrm{~mm})$,

Stimulation: duration 0.1 sec, frequency 6 stimuli/min, intensity $1.0 \mathrm{~V}$

\section{DISGUSSION}

The above mentioned fact that indirect stimulation becomes ineffective earlier than direct stimulation demonstrates that the nervous element is affected by the poison earlier than the

\footnotetext{
*, * The authors are grateful to Dr. W.P. Colvin, Burroughs Welcome Co. for generous samples of Syncurine (decamethonium preparation) and to Dr. H. Mizuta, Sankyo Pharmaceutical Co. for that of Tetrodotoxin.
} 
muscular element. The block is not due to any irreversible organic alteration. because washing can remove it. It does not seem to affect the end-plate selectively, because none of $d$ tubocurarine. decamethonium. acetylcholine, physostigmine and neostigmine antagonizes the effect of tetrodotoxin. It was observed in experiments in vitro on various enzymes of the nervous system of the guinea pig that choline acetylase is most sensible to the poison, being inhibited by it in concentration of $1 \times 10^{-i}$ (7). However, the present results show that the poison is not antagonized by acetylcholine on the neuro-muscular preparation. Even though on another enzyme, Kobinger and Kraupp (8) report similarly that polymethylene-bis-carbaminoylcholine inhibits the colinesterase activity in ititro, but it does not have any muscarinic action in i'vo. Thus, there can be difference between the action of acetylcholine produced inside the neuro-musclar system and that of acetylcholine brought from outside. But it also is probable that tetrodotoxin has another mechanism of action, beside that of inhibiting production of acetylcholine at the nerve ending.

Compounds effective for myasthenia gravis, i.e. epinephrine, ephedrine, potassium chloride, guanidine and glycocoll were not able to remove the action of the poison either.

Also, it could not be counteracted by veratrine which causes hyperirritability of the muscle by increasing the negative after-potential of the muscular impulse.

\section{CONCLUSION}

1. Effect of tetrodotoxin, a globefish poison, on the mammalian neuro-muscular system was studied with Bülbring's phrenic-diaphragm preparation.

2. The excitatory threshold rose earlier against indirect stimulation than against direct stimulation.

3. The blocking effect of the poison could be removed by washing.

4. The blocking effect of the poison could not be antagonized by none of the following compounds: $d$-tubocurarine, decamethonium, neostigmine. physostigmine, acetylcholine, calcium chloride, potassium chloride. epinephrine. ephedrine, guanidine, glycocoll and veratrine.

\section{REFERENCES}

1) Takahachi. J. \& IN JKo. Y.: .trch. exp. Path. u. Pharmakol. 26. 401, 1890;

2) ITAKURA. T.: Mitteil. d. Med. Fakul. d. Kaiserl. L nt. Trekyo 17. 460 1917:

3) ISHIHARA. F.: Tokyo Igakkat Zasshı 31, 7171917 (Japanese)

4. YANO, I. Fukuoka Ikadatgaku Zasshı 30. 1669,1937 ,Iapanese

5. Matsumura. M. \& Yamamoto. S. Jap. .l. Pharmarol. 4. 621954

6 BÜlbring. E. Brit. J. Pharmacrl. 1. 381946

7 NAGANO. H. Folia pharmacol. ,aprm. 52. 5701956 ,.Japanese)

8. Kobinger. W \& KRAUPP. (). Arch. exp Path. u. Pharmakol 225. 107 1955, 